

\title{
EXAFS Investigation of the Ni2+ Environment in Heavy-Meta1 Fluoride Glasses
}

M. Buñuel, R. Cases, J. García, M. Proietti, J. Solera

\section{To cite this version:}

M. Buñuel, R. Cases, J. García, M. Proietti, J. Solera. EXAFS Investigation of the Ni2+ Environment in Heavy-Meta1 Fluoride Glasses. Journal de Physique IV Proceedings, 1997, 7 (C2), pp.C2-1219-C21220. 10.1051/jp4:19972202 . jpa-00255274

\section{HAL Id: jpa-00255274 https://hal.science/jpa-00255274}

Submitted on 1 Jan 1997

HAL is a multi-disciplinary open access archive for the deposit and dissemination of scientific research documents, whether they are published or not. The documents may come from teaching and research institutions in France or abroad, or from public or private research centers.
L'archive ouverte pluridisciplinaire HAL, est destinée au dépôt et à la diffusion de documents scientifiques de niveau recherche, publiés ou non, émanant des établissements d'enseignement et de recherche français ou étrangers, des laboratoires publics ou privés. 


\title{
EXAFS Investigation of the $\mathrm{Ni}^{2+}$ Environment in Heavy-Metal Fluoride Glasses
}

\author{
M.A. Buñuel, R. Cases, J. García, M.G. Proietti and J.A. Solera \\ Instituto de Ciencia de Materiales de Aragón, CSIC-Universidad de Zaragoza, pza. S. Francisco s.n., \\ 50009 Zaragoza, Spain
}

\begin{abstract}
The rickel local structure of $\mathrm{Ni}$ doped heavy metal fluoride glasses of the type $\mathrm{ZrF}_{4}-\mathrm{BaF}_{2}-\mathrm{LaF}_{3}-\mathrm{NaF}_{-}\left(\mathrm{BaCl}_{2}\right)$ as a function of the chlorine content has been determined by means of $x$-ray absorption spectroscopy. Nickel ion is surrounded by six halides in octahedral configuration in all the samples studied. At low chlorine content nickel is coordinated only by fluorine, at intermediate concentrations $\mathrm{Ni}$ coordinate three fluorine and three chlorine presumably in trigonal symmetry and at high $\mathrm{Cl}$ concentrations by only six chlorine. Our results correlates with the optical absorption spectra of $\mathrm{Ni}^{2+}$ which shows that the ${ }^{1} \mathrm{E}$ band characteristic of $\mathrm{Ni}^{2+}$ coordinated by six fluorine atoms changes in shape and energy position with the $\mathrm{Cl}$ content.
\end{abstract}

\section{INTRODUCTION}

Since heavy-metal fluoride glasses were discovered, a great number of investigations have characterized the structural, optical, mechanical and electrical properties of these materials $[1,21$. The technical applications of these glasses in a wide range of optical devices, as fiber optics, lasers and amplifiers, have promoted the investigation in some specific aspects [3]. Generally, structural investigations have been carried out mainly on binary $\mathrm{ZrF}_{4}-\mathrm{BaF}_{2}$ based glasses, while most potential applications require multicomponent fluoride glasses. These materials can be doped with $3 \mathrm{~d}$ transition metal ions, as $\mathrm{Ni}^{2+}$, that can ocuppy different sites with different environments. Moreover, few work has been performed on glasses containing halogens different from fluorine, as chlorine or bromine, whose configuration around the $3 \mathrm{~d}$ ions of the matrix is so important in the determination of their optical properties. The absorption spectrum of $\mathrm{Ni}^{2+}$ embedded in a glass matrix containing fluorine ions, shows an ${ }^{1} \mathrm{E}$ band, corresponding to forbidden transitions ${ }^{3} \mathrm{~A}_{2}{ }^{-1} \mathrm{Ea}$ at $14950 \mathrm{~cm}^{-1}$. When chlorine is added, to the glass, the ${ }^{1} \mathrm{E}$ band changes its shape and moves to lower energies for increasing $\mathrm{Cl}$ amounts incorporated to the matrix. This behaviour is consistent with an octahedral symmetry of the $\mathrm{Ni}$ atom surrounded by $6 \mathrm{~F}$ ions, that gradually changes to trigonal upon introduction of $\mathrm{Cl}$, to turn again octahedral, with an ${ }^{1} \mathrm{E}$ band at $12700 \mathrm{~cm}^{-1}$, when the substitution of $\mathrm{F} \mathrm{by} \mathrm{Cl}$ is complete and the octahedral symmetry is restored.

We present here the determination of the local structure around the nickel atom as a function of the chlorine content of the glasses by means of X-ray absorption spectroscopy. As we will show later, our results confirm the changes of environment of the Ni atom suggested by the optical data.

\section{EXPERIMENTAL}

Multicomponent glasses of formula $52 \mathrm{ZrF}_{4}-20 \mathrm{BaF}_{2}-4.5 \mathrm{LaF}_{3}-21 \mathrm{NaF}-\mathrm{x}\left(\mathrm{BaCl}_{2}\right)$ in which only the chlorine content has been modified by adding the appropiate $\mathrm{BaCl}_{2}$ amount and doped with an $1 \%$ weight of $\mathrm{Ni}^{2+}$ were prepared by standart methods. The samples studied with the $\mathrm{Cl}$ content as function of the total halide content determined by $\mathrm{x}$-ray fluorescence analysis of the samples are given in Table 1. X-ray absorption spectra at the nickel $\mathrm{K}$ edge of glasses and the model compounds $\mathrm{NiF}_{2}$ and $\mathrm{NiCl}_{2}$ were carried out at the Synchrotron Radiation Source of the Daresbury Laboratory. The measurements were performed in the fluorescence mode at the Station 8.1 which is equipped with an intrinsic germanium detector.

The experimental EXAFS spectra were extracted from the raw spectra by following standard methods. In order to separate the different oscillatory contributions, the EXAFS signals were Fourier transformed by using in all cases the same Gaussian window with the same limits $\left(\mathrm{k}\right.$ min= $2 \AA^{-1}, \mathrm{k}$ max $\left.=12 \AA^{-1}\right)$. The modulus of the F.T. are not corrected for the central atom phase shifts so the peaks are shifted from the true $R$ values.

The first shell contribution has been analyzed by curve fitting of the filtered EXAFS signal with the signals obtained by using theoretical phases and amplitudes from FEFF 3.11 code. The goodness of the theoretical phases has been checked by analysis of the first shell coordiation of $\mathrm{Ni}$ in $\mathrm{NiCl}_{2}$ and $\mathrm{NiF}_{2}$ reference samples. Comparison of the XANES spectra were performed after background subtraction and normalization.

\section{RESULTS AND CONCLUSIONS.}

The EXAFS spectra of the nickel doped fluorine glasses are characterized by a main oscillation whose frequency increases with the chlorine content. The modulus of the F.T.compared with the model compouds $\mathrm{NiF}_{2}$ and $\mathrm{NiCl}_{2}$ are shown in figure 1 . The 
F.T. display a main peak correponding to the first coordinatin shell which moves from $R=1.58 \AA$ for NiF 2 , the non-chlorine doped and the lowest chlorine doped samples to $1.95 \AA$ for the highest $\mathrm{Cl}$-doped glasses and $\mathrm{NiCl}_{2}$. This figure shows qualitatively the correlation between the $\mathrm{Cl}$ content of the glasses with the position of the main peak showing the evolution from nickel surrounded by only fluorine atoms to nickel completely coordinated by chlorine.
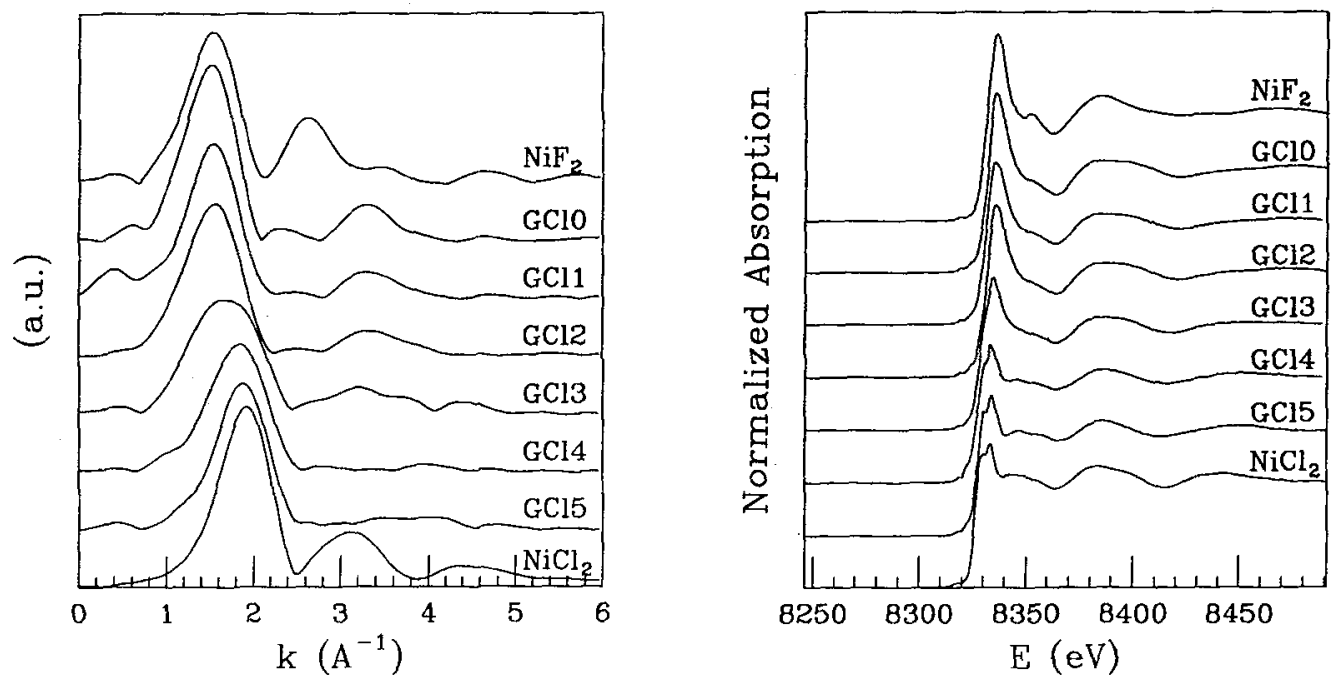

Figure 1: Modulus of the Fourier Transform of the EXAFS spectra (left panel) and Normalized Ni K edge XANES spectra (right panel) of nickel doped fluorine glasses compared with $\mathrm{NiCl}_{2}$ ad NiF 2 reference samples. The spectra are ordered, from the top to the bottom, in sequence of glass chlorine content.

Table 1: Best fit values obtained for coordination numbers $(\mathbb{N})$, interatomic distances $(R)$ and Debye-Waller factors $\left(\sigma^{2}\right)$ of nickel doped fluoride glasses. The errors on the fit parameters are $\Delta \mathrm{N} / \mathrm{N}=10 \%, \Delta R=0.02 \AA, \Delta \sigma^{2}=0.03 \AA^{2}$ for the whole set of samples.

\begin{tabular}{lccccc}
\hline Sample & $\% \mathrm{Cl} /(\mathrm{F}+\mathrm{Cl})$ & nearest neighbour atom & $\mathrm{N}$ & $\mathrm{R}(\AA)$ & $\sigma^{2}\left(\AA^{2}\right)$ \\
\hline $\mathrm{NiF} 2$ & 0. & $\mathrm{~F}$ & 6 & 2.02 & 0.008 \\
$\mathrm{GCl0}$ & 0. & $\mathrm{~F}$ & 6 & 2.00 & 0.006 \\
$\mathrm{GCl1}$ & 0.35 & $\mathrm{~F}$ & 6 & 2.01 & 0.007 \\
$\mathrm{GCl} 2$ & 0.38 & $\mathrm{~F}$ & 6. & 2.01 & 0.007 \\
$\mathrm{GCl} 3$ & 0.54 & $\mathrm{~F}$ & 3 & 1.99 & 0.006 \\
& & $\mathrm{Cl}$ & 3 & 2.38 & 0.008 \\
$\mathrm{GCl}$ & 2.99 & $\mathrm{Cl}$ & 6. & 2.35 & 0.011 \\
$\mathrm{GCl5}$ & 7.93 & $\mathrm{Cl}$ & 6 & 2.36 & 0.011 \\
$\mathrm{NiCl} 2$ & 100 & $\mathrm{Cl}$ & 6 & 2.38 & 0.007 \\
\hline
\end{tabular}

First shell contribution was extracted by Fourier filtering of the main peak and analyzed by least-squares minimization of the difference between experimental and theoretical data. The errors of the fit parameters were evaluated by changing each variable, while refining the others, until the residual minimum was doubled.

The best fit results, reported in Table 1 , show the change of coordination of the nickel atom from six fluorine atoms at $2.0 \AA$ for the chlorine undoped and the less doped sample, the coordiation three $\mathrm{F}$ atoms plus three $\mathrm{Cl}$ atoms for the $\mathrm{GCl} 3$ glass up to the GCl5 sample which is completely surrounded by six chlorine atoms at $2.36 \AA$.

The normalized XANES spectra of the different glasses with the model compounds are compared in fig. 1. We observe that the XANES spectra of the GCl0 sample is characteristic of octahedral coordination of light atoms showing a main peak as the pure $\mathrm{NiF}_{2}$ model compound. When the $\mathrm{Cl}$ content of the glasses increases the spectral shape changes to that of $\mathrm{NiCl}_{2}$ being very similar to the GCl4 and GCl5 samples. These results corroborate the EXAFS analysis and show the change to octahedral chlorine geometry for the highest chlorine doped glasses.

Summarizing, the EXAFS and XANES results show that the environment of the Ni atom changes from purely octahedra with six fluorine atoms at low chlorine content to trigonal (three fluorine and three chlorine atoms) for intermediate concentrations to tum out again octahedral for the samples with highest $\mathrm{Cl}$ content.

\section{References}

[1] M. Poulain, J. Lucas, P. Brun, Mater. Res. Bull. 10 (1975) 243.

[2] M. Poulain, J. Non-Cryst. Solids 56 (1983) 1.

[3] J. Lucas, J. Non-Cryst. Solids 80 (1986) 83. 